\title{
ANALISIS VISUAL FOTOGRAFI PRE-WEDDING KONSEP STREET FOTOGRAFI KARYA NATURALLICA PHOTO
}

\author{
Muhammad Maliq Fajar*1, Arief Johari ${ }^{2}$, Harry Atmami ${ }^{3}$ \\ Universitas Nusa Putra ${ }^{1}$, \\ *Corresponding author: maliqfajar02@gmail.com, Sukabumi, Indonesia
}

\begin{abstract}
Abstrak. Fotografi pre-wedding merupakan salah satu bagian dari suatu rangkaian kegiatan sebelum memasuki tahap pernikahan. Untuk saat ini fotografi Pre-wedding sudah sangat populer untuk mendukung moment sebelum hari pernikahan. Baru-baru ini muncul suatu konsep fotografi dengan menggabungkan antara fotografi pre-wedding dengan street fotografi yang mungkin akan menjadi salah satu inovasi terbaru untuk dunia fotografi pre-wedding. Fotografi pre-wedding konsep street fotografi pada dasarnya adalah sebuah kegiatan sehari-hari dari pasangan tersebut yang sengaja didokumentasikan dalam bentuk foto, untuk mempertahankan definisi dari street fotografi itu sendiri maka tetap mempertahankan sebuah realitas yang ada tetapi dengan subjek diatur untuk melakukan pose oleh seorang fotografer.
\end{abstract}

Kata kunci: Fotografi Wedding, Fotografi Pre-wedding, Fotografi Jalanan

\begin{abstract}
Pre-wedding photography is one part of a series of activities before entering the wedding stage. For now, pre-wedding photography is very popular to support the moments before the wedding day. Recently, a concept of photography emerged by combining pre-wedding photography with street photography which might be one of the newest innovations in the world of pre-wedding photography. Pre-wedding photography, the concept of street photography, is basically a daily activity of the couple which is deliberately documented in the form of photos, to maintain the definition of street photography itself, it still maintains a reality but with the subject arranged to pose a pose by a photographer.
\end{abstract}

Keywords: Wedding Photography, Pre-wedding Photography, Street photography

\section{Pendahuluan}

Dalam dunia fotografi sebenarnya tidak ada istilah untuk fotografi pre-wedding, yang ada hanyalah fotografi wedding, dengan perkembangan yang ada di indonesia membuat trend fotografi ini sendiri menjadi sangat diminati. Fotografi pre-wedding sendiri di indonesia dikenal sebagai pemotretan sebelum mejelang hari pernikahan. Fotografi pre-wedding memang banyak diminati oleh para calon pengantin untuk membuat suatu moment kedua pasangan menjelang hari pernikahan, kemudian dengan hadirnya berbagai penyedia jasa fotografi / perusahaan fotografi (vendor) menjadi keuntungan yang didapat tidak hanya dari hari pernikahan saja (wedding).

Untuk memenuhi permintaan klien dalam hal fotografi pre-wedding membuat penyedia jasa fotografi membuat konsep berulang-ulang dan nyaris sama, hal tersebut menjadi salah satu kelemahan seorang penyedia jasa fotografi dikarenakan klien bosan dan tidak ingin 
memiliki konsep yang sama dengan yang lain. Pada dasarnya fotografi pre-wedding hanyalah sebuah pelengkap untuk calon pengantin yang akan melangsungkan pernikahan, namun bagi sebagian kalangan hal tersebut menjadi hal tepenting dalam sebuah rangkaian acara pernikahan.

Hal yang dikejar dalam fotografi pre-wedding adalah nilai artistik foto dengan objek mempelai yang sedang bermesraan atau berpose bak model fashion. Tidak hanya itu, unsur lokasi pemotretan yang mendukung dan olah digital juga semakin membuat fotografi jenis ini menjadi lebih bernilai.

Untuk menghadapi konsep yang digunakan sama dengan yang lain maka munculah suatu konsep dengan menggabungkan pre-wedding fotografi dengan street fotografi. Street fotografi sendiri merupakan suatu aliran fotografi yang mengungkapkan suatu kejadian di jalan secara realitas yang diambil tanpa sebuah pengarahan ( candid). Aliran fotografi ini berawal dari Eropa, saat Eugene Atget ( pelopor fotografi dokumenter ) mulai mengabadikan suasana jalanan kota Paris sekitar tahun 1890an hingga 1920an. Foto-foto Atget banyak mengambil obyek arsitektural, dan hanya sedikit sekali mengambil manusia sebagai subyek foto. Hal ini berbeda sekali dengan fotografi jalanan kontemporer yang dikenal sekarang, di mana hampir selalu menyertakan manusia sebagai subyek fotonya. Henri Cartier-Bresson mulai memasukkan unsur manusia dan komposisi surealismenya dalam foto-fotonya yang diambil sejak awal tahun 1940an, hingga akhirnya aliran inilah yang makin berkembang hingga bentuk fotografi jalanan yang populer hingga sekarang. Di Indonesia, aliran fotografi ini masih tergolong muda dibandingkan aliran lainnya. Fotografi jalanan baru mulai berkembang di Indonesia pada sekitar tahun 1990an, dan makin populer pada dekade pertama tahun 2000an seiring berkembangnya teknologi fotografi digital. Dan kegiatan untuk memotret kehidupan di ruang publik sudah mulai dilakukan sejak abad ke-19 ketika Jacques Mande Daguerre mengambil foto jalanan dari jendela studinya.

Meskipun demikian, semua sepakat bahwa orang yang berhak mendapatkan gelar "Bapak Fotografi Jalanan" adalah Henri Cartier-Bresson. la-lah yang pada tahun 1950 mengeluarkan sebuah konsep yang bernama "decisive moment" atau momen kulminasi yang hingga kini terus bergaung di kalangan para penggemar genre ini.

\section{Metode}

Untuk melakukan analisis pada permasalahan fotografi pre-wedding dengan konsep street fotografi, maka dilakukan penelitian dengan metode kualitatif untuk menganalisis visual fotografi pre-wedding konsep street fotografi.

Nurhadi (2017: 44) menjelaskan semiotik metode memberi artinya memberi tanda dan membujuk yang lain menggunakan arti tanda. Tujuan menggunakan metode ini dikarenakan metode tersebut memiliki karateristik yang sesuai dengan analisis visual yang akan dilakukan untuk memperoleh data-data yang tepat. Untuk memperoleh data tersebut dengan menjelaskan masalah atau gejala yang ada dengan mengumpulkan, menganalisis, dan kemudian menginterpretasikan data yang diperoleh, maka metode deskriptif digunakan dalam penelitian ini.

Menurut Strauss (2019:3), temuan-temuan penelitiannya tidak diperoleh melalui prosedur statistik dan bentuk hitungan lainnya. Dalam penelitian kualitatif ini, menurut Sugiyono (2019:4) peneliti sendiri yang menjadi instrumen dengan kata lain instrumennya adalah orang atau human instrument. Analilis kualitatif deskriftif lebih ditekankan pada kesimpulan dedukatif dan induktifantara hubungan fenomena yang diamati dengan logika alamiah (Erlyana \& Setiawan 2019:3). 


\section{Teknik Pengumpulan Data}

Dalam tahap pengumpulan data penulis melakukan teknik pengumpulan data yang diperlukan untuk menganalisis foto tersebut maka sebagai berikut :

1. Studi Pustaka

Studi pustaka digunakan untuk mendapatkan informasi dari berbagai sumber seperti, website maupun buku untuk mendapatkan informasi yang akan dilakukan dalam penelitian ini.

2. Observasi

Pada teknik observasi penulis mengumpulkan data berupa foto-foto yang sudah ada yang kemudian akan dilakukan penelitian sebagai sumber untuk menganalisis visual dari fotografi pre-wedding konsep street fotografi. observasi yang dilakukan penulis bersifat non partisipatif, di mana penulis tidak memiliki ikatan atau ikut berpartisipasi dalam proses pembuatan desain maupun aktifitas perusahaan.

\section{Analisis Data}

Fotografi pre-wedding konsep street fotografi yang akan dianalisis pada foto naturallica.photo meliputi subjek, objek, sudut pengambilan gambar (angle), pencahayaan (lighting), peralatan, editing, tipografi (watermark) dan komposisi pengaturan kamera seperti ISO, Aperture, dan Shutter Speed.

1. Analisis subjek dilakukan untuk mengetahui ketepatan dalam penggunaan fashion dan juga pose yang diarahkan.

2. Analisis objek dilakukan untuk mengetahui ketepatan pendukung subjek.

3. Analisis sudut pengambilan gambar (angle) dilakukan untuk mengetahui ketepatan arah sudut pengambilan gambar pada foto.

4. Analisis pencahyaan dilakukan untuk mengetahui jenis pencahayaan yang tepat untuk diterapkan pada konsep tersebut.

5. Analisis peralatan dilakukan agar dapat mengetahui keefektifitasan peralatan yang digunakan.

6. Analisis editing dilakukan untuk mengetahui faktor pendukung agar sebuah foto menjadi menarik.

7. Analisis tipografi pada foto dilakukan untuk mengetahui fungsi, jenis huruf, ragam huruf, ukuran huruf, penempatan, dan kemudahan teks untuk dibaca.

8. Analisis komposisi digunakan untuk mengetahui komposisi yang digunakan seorang fotografer dalam pengambilan sebuah foto.

9. Dan yang terakhir adalah analisis pada Exposure pengaturan kamera (segitiga exposure) agar mengetahui ketepatan yang sesuai untuk foto tersebut yang meliputi ISO, Aperture, dan Shutter Speed yang digunakan.

\section{Hasil Dan Pembahasan}

\section{Teori Fotografi}

Fotografi berasal dari bahasa Yunani, yaitu "Fos" yang artinya cahaya dan "Grafo" yang artinya melukis atau menulis. Sedangkan dalam kamus Bahasa Indonesia, arti fotografi adalah seni atau proses penghasilan gambar dan cahaya pada film. Secara garis besar arti fotografi merupakan suatu proses untuk menghasilkan gambar atau foto dari suatu obyek dengan merekam pantulan cahaya yang mengenai obyek tersebut pada media yang peka cahaya. Fotografi juga merupakan gambar, foto merupakan alat visual efektif yang dapat 
memvisualkan sesuatu lebih konkrit dan akurat, dapat mengatasi ruang dan waktu. Sesuatu yang terjadi di tempat lain dapat dilihat oleh orang jauh melalui foto setelah kejadian itu berlalu. Menurut Graham Clarke dalam bukunya The Photograph (1997:11) pernah menyebutkan istilah untuk fotografi yaitu "light-writing" yang secara harafiah dapat diartikan "melukis dengan cahaya".

Sebagai media yang terbilang baru saat itu kehadiran fotografi dianggap akan mengakhiri kejayaan seni lukis yang terlebih dahulu muncul, hal ini diperkuat dengan pernyataan salah seorang pelukis Perancis, De la Roche bahwa : "From today painting is dead." Meski tidak sepenuhnya benar namun kemunculan kekhawatiran sangat beralasan bila dilihat dari keunggulan-keunggulan teknis yang dimiliki fotografi saat itu (Soedjono, 2007:4).

Fotografi terus berkembang dengan keunikan dan kekhasannya. Hal-hal yang hampir serba mekanis menjadi keunggulan tersendiri bagi medium fotografi. Fotografi mengolaborasikan berbagai aspek pendukung dalam penciptaannya. Mekanikal kamera, kemampuan teknis penggunaan kamera, dan kemampuan mengolah ide, semuanya merupakan bagian dari proses kreativitas dalam peciptaan karya fotografi (Aloysius Assyu, 2017:4)

\section{Fotografi Pre-wedding}

Kata "Pre" dapat diartikan sebagai sebelum, sedangkan "wedding" dapat diartikan sebagai pernikahan, jadi fotografi pre-wedding merupakan sebuah foto yang diambil sebelum menjelangnya hari pernikahan, fotografi pre-wedding digunakan sebagai perekam sebuah kejadian yang diambil secara sengaja dengan mengatur kedua subjek dengan berbagai pose.

Sebenarnya fotografi pre-wedding yang pada dasarnya merupakan sebuah kegiatan sehari-hari dari pasangan tersebut yang sengaja didokumentasikan dalam bentuk foto. Biasanya hasil dari foto-foto tersebut digunakan sebagai tambahan dalam pembuatan undangan, pajangan dalam bentuk cetak berukuran 16R, ataupun keperluan unggah sosial media. Dalam dunia fotografi sebenarnya tidak ada istilah untuk fotografi pre-wedding, yang ada hanyalah fotografi wedding, dengan perkembangan yang ada di indonesia membuat trend fotografi ini sendiri menjadi sangat diminati.

\section{Fotografi Jalanan ( Street photography)}

Fotografi Jalanan ( Street photography) merupakan fotografi yang mendokumentasikan kegiatan di jalanan secara realitas atau apa adanya, bisa juga di taman kota, dipasar, maupun di terminal dan sebagainya. Menurut Thomas Leuthard (2017:1), street photography hanyalah dokumentasi kehidupan di depan umum dengan cara yang jujur. Ciri dari fotografi ini dilakukan diruang terbuka di keramaian perkotaan. Namun tidak hanya di keramaian kota saja, tentunya dapat di lakukan dipedesaan asalkan berkaian dengan kehidupan di jalanan dengan realitasnya masing-masing.

Melalui fotografi jalanan dapat memperlihatkan kejadin secara nyata pada hari itu, dan dapat juga menampilkan kesan masa lampau dengan bangunan-banguan tua maupun masa yang akan mendatang ditampilkan dengan segi berpakaian maupun bangunan-bangunan yang akan baru dibangun. Umumnya diruang publik kita akan menemukan beragam orang dengan pekerjaan, kegiatan, cara berpakaian, agama dan lainya berbeda yang tentunya menjadi keunggulan atau sebuah keunikan tersendiri.

Fotografi ini biasanya dilakuakn secara diam-diam atau candid agar subjek terlihat natural apa adanya, jika subjek mengetahui dirinya akan difoto maka subjek biasanya agak merubah ekspresi, tentu ini mengurangi definisi dari fotografi jalanan yang dilakukan dengan apa adanya. 


\section{Teknik Dasar Fotografi}

Menghasilkan suatu foto tentu tidak semudah yang dibayangkan, maka dengan itu seorang fotografer harus menguasai teknik dasar dakam fotografi agar mendapatkan hasil terbaik. Hal mendasar yang harus dikuasai yaitu Exposure meliputi ISO, Aperture (Diafragma), dan Shutter Speed. Exposure merupakan jumlah cahaya yang diizinkan masuk ke kamera dan mengenai sensor (Suzy Clement 2014:24).

1. ISO

ISO merupakan sensitifitas sensor terhadap cahaya. Semakin tinggi angka pada ISO maka akan semakin sensitif, dan sebaliknya semakin kecil angka ISO maka akan kurang sensitif maka diperlukan cahaya yang lebih banyak seperti kondisi pada siang hari (Suzy Clement 2014:32). Pada ISO terdapat kekurangan maupun kelebihan. Untuk kekurangannya semakin tinggi angka ISO maka akan mempengaruhi kualitas foto yang akan terdapat noise dan grain yang muncul dalam foto. sedangkan untuk kelebihannya semakin kecil ISO maka tingkat noise akan berkurang dan foto terlihat tajam. Angka ISO biasanya dimulai dari angka 100 hingga seterusnya.

2. Aperture (Diafragma)

Aperture merupakan jalur keluar masuknya cahaya melalui lensa yang dapat terbuka dan tertutup. Aperture juga merupakan ukuran seberapa besar diafragma terbuka, yang diukur dengan f-stop. Angka f-stop sangat mempengaruhi cahaya yang masuk, semakin kecil angka f-stop maka akan semakin besar terbuka diafragmanya tentu cahaya yang masuk pun akan semakin banyak. Angka aperture dimulai f/22 merupakan aperture (bukaan) paling kecil, dan angka aperture f/1.2 merupakan (bukaan) paling lebar (Suzy Clement 2014:30).

\section{Shutter Speed}

Shutter Speed merupakan seberapa cepat cahaya yang bisa di terima oleh kamera dan perhitungan jumlah waktu shutter speed digunakan untuk satu kali pemotretan (jepret) selama shutter tetap terbuka. Satuan perhitungan shutter speed yaitu seper sekian detik. Sebagai contoh $1 / 500$ detik merupakan ukuran shutter speed paling cepat (shutter terbuka paling cepat pada satu periode waktu) dibandingkan dengan $1 / 8$ detik (Suzy Clement 201:24)..

\section{Komposisi Fotografi}

Komposisi merupakan cara untuk mengatur setiap elemen dari suatu foto dalam satu frame. Komposisi dalam fotografi sangat banyak dan beragam, tentunya digunakan sesuai dengan kebutuhan yang diperlukan (Suzy Clement, 2014:38).

1. The Rule Of Third (Aturan Sepertiga)

Komposisi The Rule Of Third (Aturan Sepertiga) merupakan komposisi yang paling dasar dan sering digunakan, biasanya dengan membuat garis imajiner dengan membagi foto menjadi tiga secara horizontal dan vertikal dan menempatkan elemen terpenting dalam foto sepanjang garis imajiner ataupun pada titik-titik dimana garis-garis tersebut saling berpotongan.

\section{Leading Line (Garis leading)}

Garis leading biasanya terbentuk dari objek sekitar yang ada secara alami membuat foto memikat siapa saja yang melihat foto tersebut, biasanya berupa barisan kursi atau meja, deretan lampu, barisan alat makan, bahkan lorong-lorong dan lain sebagainya. 


\section{Framing}

Framing merupakan teknik komposisi yang digunakan dengan cara menggunakan objek lain dalam sebuah frame sebagai subjek utama dalam sebuah foto. sebagai contoh seperti bangunan ataupun benda lain di sekitar tempat dilakukannya pemotretan.

4. Simetri dan Pola

Simetri dan pola merupakan komposisi yang didapat dari elemen-elemen grafis yang kuat seperti garis, bentuk, ataupun warna berulang.

\section{Figure To Ground}

Komposisi ini lebih menekankan pada subjek utama yang lebih menonjol dibandingkan dengan objek. Dalam artian bahwa point of interst harus telihat jelas pada subjek dibandingkan dengan background yang ada dalam satu frame foto.

\section{Fill The Frame}

Pada komposisi ini point of interst memenuhi satu frame pada foto, baik subjek maupun objek. Biasanya digunakan pada fotografi potrait.

\section{Diagonal}

Diagonal merupakan komposisi yang memiliki sifat lebih dinamis untuk menciptakan pergerakan yang baik dalam sebuah foto.

\section{Center Dominant Eye}

Pada komposisi ini memiliki ciri seperti sebuah subjek seolah-olah melihat orang yang memperhatikan foto tersebut. Dengan memanfaatkan mata subjek agar menjadi point of interst maka foto akan termasuk kedalam teknik komposisi ini.

Menurut Andy Prasetyo (2012:52-53) Pada perkembangannya, hukum gravitasi dan sudut pandangpun dilanggar dan malah menghasilkan foto yang unik. Dengan adanya the third rule bukan berarti hukum-hukum konservatif sudah punah, tapi cuma dianggap tidak lagi eyecatched. Pedoman dalam membuat konsep komposisi letak tidak ada, yang penting adalah jiwa saat membidik sudah menyatu dengan apa yang kita lihat.

\section{Analisis Foto Karya Naturallica Photo}

Dengan perkembangan zaman yang semakin pesat dalam dunia wedding photography membuat bermunculannya vendor-vendor fotografi baru penyedia jasa wedding photography yang berada di wilayah sukabumi, entah itu yang sudah mahir maupun yang amatiran, maka dari itu naturallica photo membuat suatu konsep yang pada akhirnya dapat dijadikan sarana yang efektif untuk menghadapi persaingan tersebut.

Konsep yang dilakukan oleh naturallica photo merupakan konsep yang menggabungkan antara pre-wedding photography dengan street photography. Naturallica Photo merupakan salah satu penyedia jasa fotografi (vendor fotografi) yang berlokasi di wilayah sukabumi yang menerapkan fotografi pre-wedding dengan konsep street fotografi yang merupakan salah satu subjek yang akan dilakukan pembahasan dari hasil yang telah diteliti. Walaupun belum dapat dipastikan dari mana ide ini pertama kali muncul, namun konsep yang diterapkan pada foto naturallica photo membuatnya menjadi salah satu konsep yang menarik.

Pada bahasan yang akan dilakukan meliputi analisis visual dari fotografi pre-wedding konsep street fotografi pada 7 (Tujuh) foto yang berbeda lokasi maupun pada lokasi yang sama, dengan menggunakan komposisi yang sangat baik maka dapat membuat audience 
merasakan estetika maupun pesan yang ingin disampaikan oleh fotografer lewat karya fotografi yang diambil.

Dengan hadirnya konsep gabungan antara genre pre-wedding fotografi dan street fotografi agar menjadi bahan pertimbangan kepada calon klien nantinya dan para fotografer lainnya.

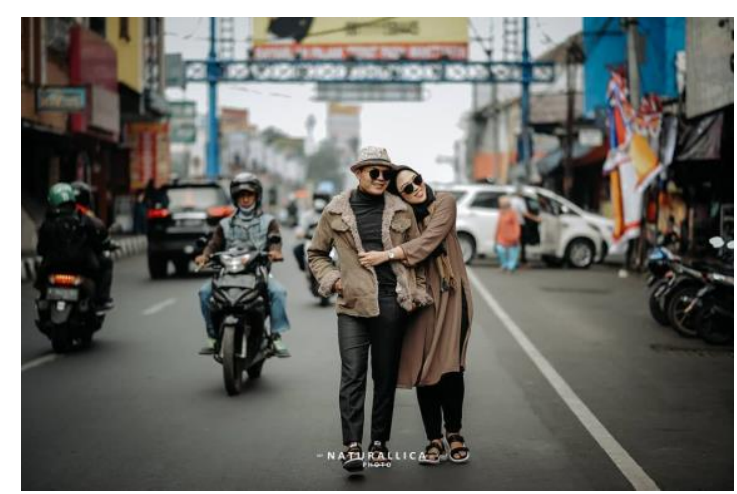

Gambar 1. Fotografi prewedding konsep street fotografi di sebuah jalan di kota sukabumi

Pasangan yang sedang melakukan sesi pemotretan pre-wedding bersamaan dengan pengendara motor dilingkungan sekitar yang sedang melintas, terlihat pasangan perempuan memeluk pasangan laki-laki dari samping. Di bagian tengah foto dibuat lebih kontras dibandingkan dengan background yang ada dalam foto agar Point of interest lebih menonjol.

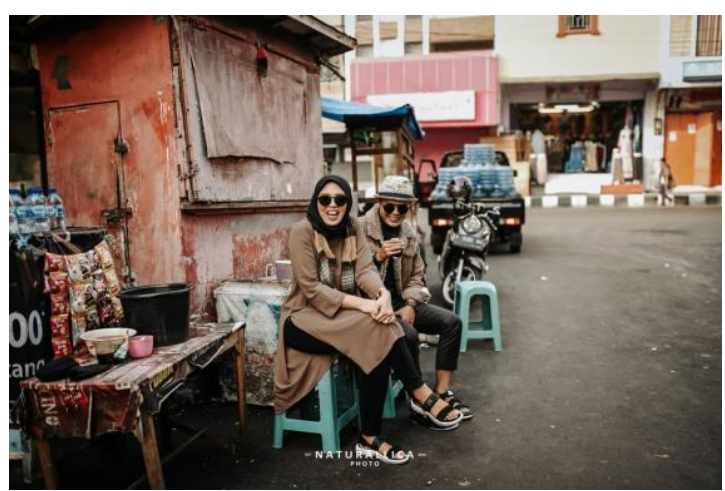

Gambar 2. Fotografi prewedding konsep street fotografi di sebuah lapak asongan pinggir jalan di kota sukabumi

Pasangan yang sedang melakukan sesi pemotretan pre-wedding di samping lapak pedagang asongan sambil menikmati secangkir kopi yang tampak sederhana. Di bagian tengah foto dibuat lebih kontras dibandingkan dengan background yang ada dalam foto agar Point of interest lebih menonjol. 


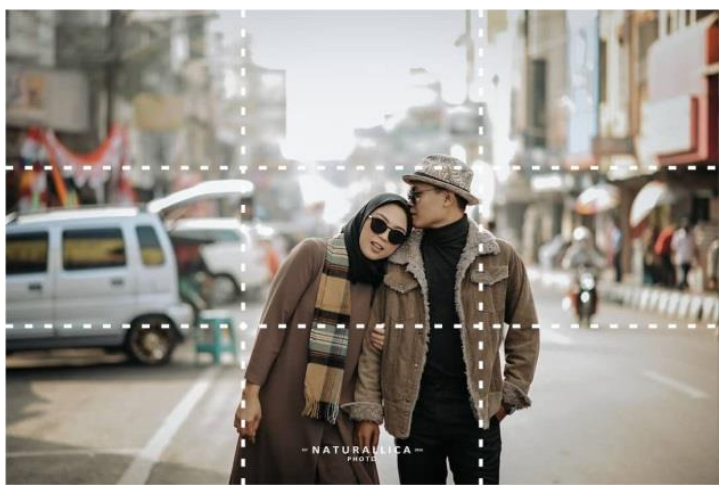

Gambar 3. Fotografi prewedding konsep street fotografi di sebuah jalan di kota sukabumi

Pasangan yang sedang melakukan sesi pemotretan dijalan perkotaan sukabumi, terlihat pasangan laki-laki mencium kening dari pasangan perempuan. Di bagian tengah foto dibuat lebih kontras dibandingkan dengan background yang ada dalam foto agar Point of interest lebih menonjol.

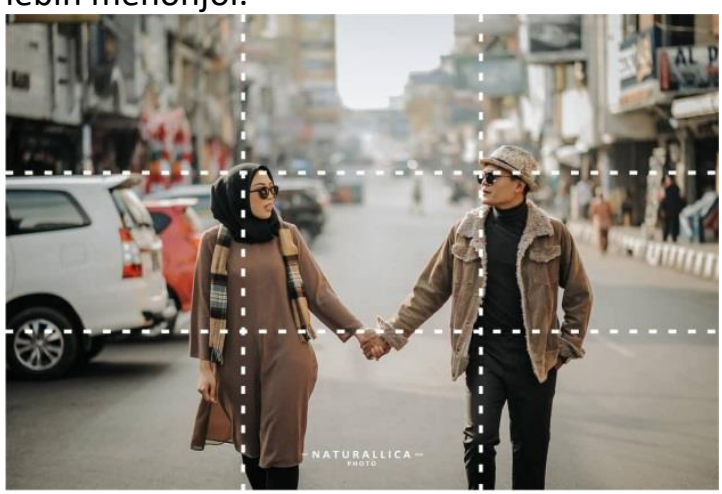

Gambar 4. Fotografi prewedding konsep street fotografi di sebuah jalan di kota sukabumi

Pasangan yang sedang melakukan sesi pemotretan dijalan perkotaan sukabumi, terlihat kedua pasangan saling berpegangan tangan. Pada sisi kanan dan kiri terlihat kendaraan yang masuk di dalam sebuah frame foto. Di bagian tengah foto dibuat lebih kontras dibandingkan dengan background yang ada dalam foto agar Point of interest lebih menonjol.

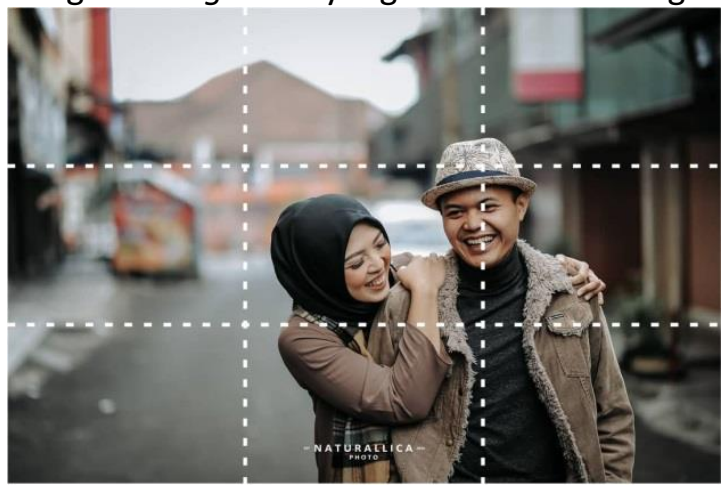

Gambar 5. Fotografi prewedding konsep street fotografi di sebuah lorong pertokoan di sukabumi

Pasangan yang sedang melakukan sesi pemotretan dijalan perkotaan pada sisi kanan dan kiri terlihat pasangan perempuan memegang pundak dari pasangan laki-laki di lorong pertokoan. Tampak ekspresi bahagia diantara pasangan tersebut menambah kesan kedekatan diantara keduanya. Di bagian tengah foto dibuat lebih kontras dibandingkan dengan background yang ada dalam foto agar Point of interest lebih menonjol. 


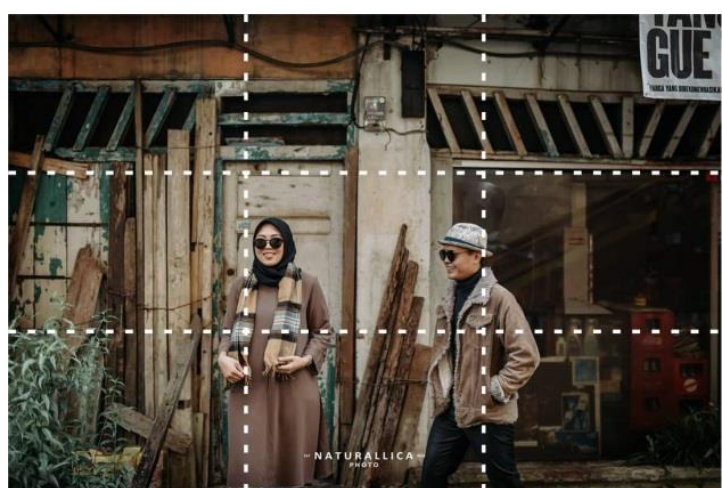

Gambar 6. Fotografi prewedding konsep street fotografi di sebuah pertokoan di sukabumi

Pasangan yang sedang melakukan sesi pemotretan didepan sebuat pertokoan yang tampak sudah tidak digunakan menimbulkan kesan masa lalu pada bangunan pertokoan tersebut, ditambah dengan beberapa balok kayu yang di simpan apa adanya. Di bagian tengah foto dibuat lebih kontras dibandingkan dengan background yang ada dalam foto agar Point of interest lebih menonjol.

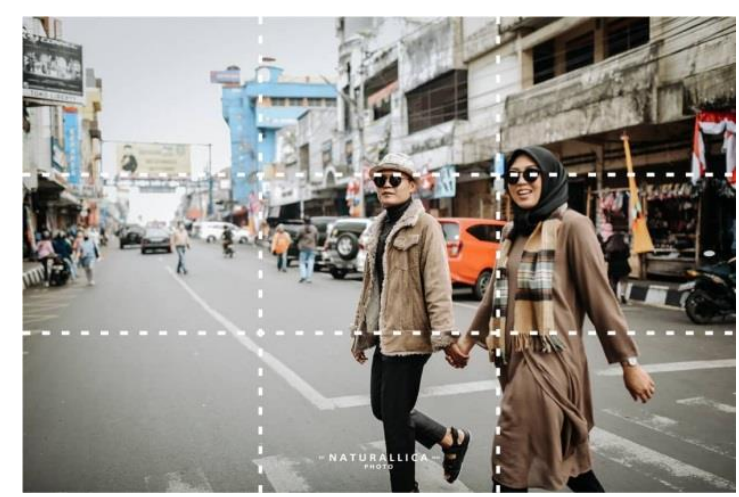

Gambar 7. Fotografi prewedding konsep street fotografi di sebuah jalan di kota sukabumi diatas jalur penyebrangan pejalan kaki (zebra cross)

Pasangan yang sedang melakukan sesi pemotretan dijalan perkotaan diatas jalur penyebrangan pejalan kaki (zebra cross), tampak keduanya saling berpegangan tangan. Di bagian subjek dibuat lebih kontras dibandingkan dengan background yang ada dalam foto agar Point of interest lebih menonjol.

Pada ketujuh gambar tersebut kita ketahui bahwa subjek adalah pasangan yang sedang melakukan sesi pemotretan pre-wedding, dengan menggunakan pakaian berwarna coklat dengan sebuah topi berjenis fedora dan kerudung berwarna hitam berkesan klasik modern membuat hal tersebut tampil dengan elegant namun seperti tidak dibuat-buat dan berkesan natural seperti pasangan yang hanya berjalan-jalan dikeramain jalan perkotaan namun tetap menimbulkan kesan romantis dan membangun chemistrynya sendiri, pada hal tersebut chemistry yang ingin ditimbulkan adalah konteks hubungan antara kedua orang atau pasangan.

Objek sekitar atau background pada foto tersebut merupakan konsep yang memang ingin ditimbulkan oleh seorang fotografer untuk mencapai definisi dari street fotografi yang memang menampilkan keadaan sekitar apa adanya, tentunya pada bagian objek (background) tidak diatur dan diarahkan. 
Kesan luas dan lebar memang ketepatan yang diambil seorang fotografer untuk menimbulkan kesan bahwa hal tersebut realitas di jalanan maka fotografer menggunakan jenis sudut pengambilan gambar yaitu Eye level yang merupakan sudut paling dasar yang sejajar dengan sudut pandang fotografer dengan format landscape, hal tersebut merupakan sudut yang normal dan umum digunakan ditambah dengan tipe shot yang lebar juga yaitu full shot dari ujung kepala hingga ujung kaki.

Untuk pencahayaan yang digunakan pada konsep foto ini dengan menggunakan daylight dan shadow yang didapat dari sinar matahari, hal tersebut sudah sangat cukup untuk pemotretan diluar ruangan (outdoor) dikarenakan sudah diimbangi dengan jenis lensa yang memiliki aperture (diafragma) yang dengan nilai yang tinggi seperti $F / 1.2, F / 1.4, F / 1.8, F / 2.8$, maka pasokan cahaya yang masuk kedalam kamera sudah sangat cukup teknik tersebut merupakan teknik yang didapat digunakan oleh konsep tersebut.

Sebuah lensa yang mengatur pasokan cahaya yang sudah disebutkan di atas sudah sangat cukup untuk memenuhi konsep tersebut, selain itu dikarenakan diafragma dengan nilai besar tersebut juga dapat menghasilkan Depth of field sempit yang merupakan bagian tertentu saja yang tampak tajam (bokeh dalam istilah fotografi) yang sangat baik untuk pemisah antara subjek dan objek namun pada bagian objek tidak blur secara total dikarenakan akan merusak konsep dari street fotografi itu sendiri. Lensa yang digunakan yaitu jenis prime lens (lensa fix) dengan focal length $35 \mathrm{~mm}, 50 \mathrm{~mm}, 85 \mathrm{~mm}, 100 \mathrm{~mm}$, hingga $200 \mathrm{~mm}$.

Untuk jenis body kamera yang digunakan antara kamera bersensor APSC, ataupun yang bersensor FullFrame, pada sensor FullFrame hal tersebut dapat menambah luas dari hasil foto yang diambil dan tentunya saja dengan kedua alat ini menambah nilai artistik dari sebuah foto menjadi nilai tambah yang baik.

Agar foto yang dihasilkan menjadi lebih baik maka foto masuk kedalam tahap editing menggunakan Adobe Photoshop yang umumnya digunakan para fotografer, dalam tahap ini hanya $10 \%-15 \%$ saja untuk dilakukan editing meliputi pencahayaan, kontras, saturasi dan lainlain, yang merupakan konsep pada foto tersebut untuk menjaga kesan natural dan tidak berlebihan dalam proses editing, pada foto tersebut sengaja ditambah vignet (efek dengan bagian hitam pada sisi-sisi foto) berkesan gelap agar foto tersebut terpusat pada subjek yang berada di tengah.

Untuk mendapatkan foto dengan exsposure tebaik pada foto tersebut umumnya digunakan pengaturan exsposure outdoor yang relatif sama dalam ketujuh foto tersebut, dengan rentang ISO 100-200, dengan diafragma F/1.2, F/1.4, F/1.8 atau F/2.8, agar dapat mengimbangi lensa dengan aperture yang nilainya besar maka shutter speed yang digunakan untuk konsep ini dimulai dari 1/100 dan seterusnya agar tidak terjadi shaking (goyang) yang menimbulkan foto menjadi miss fokus (tidak fokus) atau fokus pada lensa menjadi meleset.

Pada komposisi yang digunakan di foto tersebut merupakan teknik komposisi yang paling dasar dalam fotografi yaitu Rule Of Third, ada juga dalam beberapa foto ingin menampilkan subjek lebih menonjol dibandingan dengan objek (background). Pada kedua teknik yang digunakan dalam karya naturallica photo bertujuan agar point of interst tertuju pada pasangan tersebut.

Agar mencegah terjadinya pembajakan atau duplikasi kepemilikan, maka Naturallica Photo menempatkan nama brand mereka dalam setiap foto yang dihasilkan, biasa disebut dengan watermark yang berupa logotipe untuk menempatkan nama perusahaan tersebut (vendor fotografi). Tidak lupa juga agar semua orang termasuk klien mengetahui kapan berdirinya Naturallica Photo maka dicantumkan juga tahun berdirinya yang dipadukan dengan logotipe yang digunakan pada watermark foto tersebut. Dari watermark tersebut yang sudah pasti dibuat agar dapat terbaca dengan jelas maka digunakan jenis huruf San-Serif ragam huruf Calibri dicetak tebal agar terlihat dengan jelas untuk kemudahan dalam membaca, namun 
kekurangannya terletak pada tahun berdirinya yang tidak terlihat jelas, ini membuat pembaca agak sulit untuk membacanya.

Inilah fotografi pre-wedding dengan konsep fotografi jalanan (street photography) ketika kesederhanaan dan apa adanya yang dapat timbul di konsep ini maka telah sampailah kepada tujuan dari fotografer yang menggunakan konsep ini yang dihasilkan dalam fotonya. Pada konsep ini lebih ditekankan kepada objek jalanan dan lingkungan sekitarnya yang tampil menjadi kesan yang istimewa dengan apa adanya menjadikan keunggulan dari konsep ini, membuat konsep ini tampil sangat berbeda dan menjadi keunikan sendiri diantara konsep fotografi pre-wedding yang lainnya.

Tabel 1. Aspek Pengamatan Foto Karya Naturallica Photo.

\begin{tabular}{|c|c|c|c|}
\hline Jenis Gambar & Aspek Pengamatan & Sub Aspek & Keterangan \\
\hline & Unsur Fotografi & Komposisi & Figure To Ground \\
\hline & & Format & Landscape \\
\hline & & Angel & Eye Level \\
\hline & & Type Shot & Full Shot \\
\hline & & Camera Type & Dslr/Mirrorless \\
\hline & & Focal Lenght & $35 \mathrm{~mm} / 50 \mathrm{~mm} / 85 \mathrm{~mm} / 100 \mathrm{~mm}$ \\
\hline & & Sensor & APSC/FullFrame \\
\hline & & ISO & $100-200$ \\
\hline & & Aperture & $\mathrm{f} 1.2 / \mathrm{f} 1.4 / \mathrm{f} 1.8 / \mathrm{f} 2.8$ \\
\hline & & Shutter Speed & $1 / 100-1 / 8000$ \\
\hline \multirow[t]{8}{*}{ Gambar 1} & Unsur Subjek Dan Objek & Subjek & $\begin{array}{l}2 \text { orang, (pasangan yang sedang melakukan } \\
\text { pemotretan). }\end{array}$ \\
\hline & & Objek & $\begin{array}{l}\text { Beberapa Orang, terdiri dari pengendara } \\
\text { motor dan mobil. suasana pinggir jalan di } \\
\text { kota sukabumi. }\end{array}$ \\
\hline & Unsur Tipografi & Jenis Huruf & Sans Serif \\
\hline & & Ragam Huruf & Calibri \\
\hline & & Ukuran Huruf & $4,5 p t \& 1,5 p t$ \\
\hline & & Pengaturan Huruf & Horizontal \\
\hline & & & Scale $100 \%$ \\
\hline & & & Color Text : \#FFFFFF \\
\hline \multirow[t]{10}{*}{ Jenis Gambar } & Aspek Pengamatan & Sub Aspek & Keterangan \\
\hline & Unsur Fotografi & Komposisi & Figure To Ground \\
\hline & & Format & Landscape \\
\hline & & Angel & Eye Level \\
\hline & & Type Shot & Full Shot \\
\hline & & Camera Type & Dslr/Mirrorless \\
\hline & & Focal Lenght & $35 \mathrm{~mm} / 50 \mathrm{~mm} / 85 \mathrm{~mm} / 100 \mathrm{~mm}$ \\
\hline & & Sensor & APSC/FullFrame \\
\hline & & ISO & $100-200$ \\
\hline & & Aperture & $\mathrm{f} 1.2 / \mathrm{f} 1.4 / \mathrm{f} 1.8 / \mathrm{f} 2.8$ \\
\hline \multirow[t]{5}{*}{ Gambar 2} & & Shutter Speed & $1 / 100-1 / 8000$ \\
\hline & Unsur Subjek Dan Objek & Subjek & $\begin{array}{l}2 \text { orang, (pasangan yang sedang melakukan } \\
\text { pemotretan). }\end{array}$ \\
\hline & & Objek & $\begin{array}{l}\text { Sebuah warung kopi kecil, pertokoan, } \\
\text { sebuah mobil dan motor, gerobak dan } \\
\text { beberapa kursi dan meja. }\end{array}$ \\
\hline & Unsur Tipografi & Jenis Huruf & Sans Serif \\
\hline & & Ragam Huruf & Calibri \\
\hline
\end{tabular}




\begin{tabular}{|c|c|c|c|}
\hline & & $\begin{array}{l}\text { Ukuran Huruf } \\
\text { Pengaturan Huruf }\end{array}$ & $\begin{array}{l}4,5 p t \& 1,5 p t \\
\text { Horizontal } \\
\text { Scale } 100 \% \\
\text { Color Text : \#FFFFFF }\end{array}$ \\
\hline \multirow[t]{2}{*}{ Jenis Gambar } & Aspek Pengamatan & Sub Aspek & Keterangan \\
\hline & Unsur Fotografi & $\begin{array}{l}\text { Komposisi } \\
\text { Format } \\
\text { Angel } \\
\text { Type Shot } \\
\text { Camera Type } \\
\text { Focal Lenght } \\
\text { Sensor } \\
\text { ISO } \\
\text { Aperture } \\
\text { Shutter Speed }\end{array}$ & $\begin{array}{l}\text { Rule Of Third } \\
\text { Landscape } \\
\text { Eye Level } \\
\text { Mid Shot } \\
\text { Dslr/Mirrorless } \\
35 \mathrm{~mm} / 50 \mathrm{~mm} / 85 \mathrm{~mm} / 100 \mathrm{~mm} \\
\text { APSC/FullFrame } \\
100-200 \\
\mathrm{f} 1.2 / \mathrm{f} 1.4 / \mathrm{f} 1.8 / \mathrm{f} 2.8 \\
1 / 100-1 / 8000\end{array}$ \\
\hline \multirow[t]{2}{*}{ Gambar 3} & Unsur Subjek Dan Objek & $\begin{array}{l}\text { Subjek } \\
\text { Objek }\end{array}$ & $\begin{array}{l}2 \text { orang, (pasangan yang sedang melakukan } \\
\text { pemotretan). } \\
\text { Keramaian pinggir jalan kota sukabumi, dan } \\
\text { beberapa kendaraan mobil maupun motor. }\end{array}$ \\
\hline & Unsur Tipografi & $\begin{array}{l}\text { Jenis Huruf } \\
\text { Ragam Huruf } \\
\text { Ukuran Huruf } \\
\text { Pengaturan Huruf }\end{array}$ & $\begin{array}{l}\text { Sans Serif } \\
\text { Calibri } \\
4,5 p t \& 1,5 p t \\
\text { Horizontal } \\
\text { Scale } 100 \% \\
\text { Color Text : \#FFFFFF }\end{array}$ \\
\hline \multirow[t]{4}{*}{ Jenis Gambar } & Aspek Pengamatan & Sub Aspek & Keterangan \\
\hline & Unsur Fotografi & $\begin{array}{l}\text { Komposisi } \\
\text { Format } \\
\text { Angel } \\
\text { Type Shot } \\
\text { Camera Type } \\
\text { Focal Lenght } \\
\text { Sensor } \\
\text { ISO } \\
\text { Aperture } \\
\text { Shutter Speed }\end{array}$ & $\begin{array}{l}\text { Rule Of Third } \\
\text { Landscape } \\
\text { Eye Level } \\
\text { Mid Shot } \\
\text { Dslr/Mirrorless } \\
35 \mathrm{~mm} / 50 \mathrm{~mm} / 85 \mathrm{~mm} / 100 \mathrm{~mm} \\
\text { APSC/FullFrame } \\
100-200 \\
\mathrm{f} 1.2 / \mathrm{f} 1.4 / \mathrm{f} 1.8 / \mathrm{f} 2.8 \\
1 / 100-1 / 8000\end{array}$ \\
\hline & Unsur Subjek Dan Objek & $\begin{array}{l}\text { Subjek } \\
\text { Objek }\end{array}$ & $\begin{array}{l}2 \text { orang, (pasangan yang sedang melakukan } \\
\text { pemotretan). } \\
\text { Keramaian pinggir jalan kota sukabumi, dan } \\
\text { beberapa kendaraan mobil maupun motor. }\end{array}$ \\
\hline & Unsur Tipografi & $\begin{array}{l}\text { Jenis Huruf } \\
\text { Ragam Huruf } \\
\text { Ukuran Huruf } \\
\text { Pengaturan Huruf }\end{array}$ & $\begin{array}{l}\text { Sans Serif } \\
\text { Calibri } \\
4,5 p t \& 1,5 p t \\
\text { Horizontal } \\
\text { Scale } 100 \% \\
\text { Color Text : \#FFFFFF }\end{array}$ \\
\hline Jenis Gambar & Aspek Pengamatan & Sub Aspek & Keterangan \\
\hline Gambar 5 & Unsur Fotografi & $\begin{array}{l}\text { Komposisi } \\
\text { Format } \\
\text { Angel } \\
\text { Type Shot } \\
\text { Camera Type }\end{array}$ & $\begin{array}{l}\text { Rule Of Third } \\
\text { Landscape } \\
\text { Eye Level } \\
\text { Mid Shot } \\
\text { Dslr/Mirrorless }\end{array}$ \\
\hline
\end{tabular}




\begin{tabular}{|c|c|c|c|}
\hline & & Focal Lenght & $35 \mathrm{~mm} / 50 \mathrm{~mm} / 85 \mathrm{~mm} / 100 \mathrm{~mm}$ \\
\hline & & Sensor & APSC/FullFrame \\
\hline & & ISO & $100-200$ \\
\hline & & Aperture & $\mathrm{f} 1.2 / \mathrm{f} 1.4 / \mathrm{f} 1.8 / \mathrm{f} 2.8$ \\
\hline & & Shutter Speed & $1 / 100-1 / 8000$ \\
\hline & \multirow[t]{2}{*}{ Unsur Subjek Dan Objek } & Subjek & $\begin{array}{l}2 \text { orang, (pasangan yang sedang melakukan } \\
\text { pemotretan). }\end{array}$ \\
\hline & & Objek & Lorong sebuah Pertokoan \\
\hline & \multirow[t]{4}{*}{ Unsur Tipografi } & Jenis Huruf & Sans Serif \\
\hline & & Ragam Huruf & Calibri \\
\hline & & Ukuran Huruf & $4,5 p t \& 1,5 p t$ \\
\hline & & Pengaturan Huruf & $\begin{array}{l}\text { Horizontal } \\
\text { Scale } 100 \% \\
\text { Color Text : \#FFFFFF }\end{array}$ \\
\hline \multirow[t]{2}{*}{ Jenis Gambar } & Aspek Pengamatan & Sub Aspek & Keterangan \\
\hline & Unsur Fotografi & $\begin{array}{l}\text { Komposisi } \\
\text { Format } \\
\text { Angel } \\
\text { Type Shot } \\
\text { Camera Type } \\
\text { Focal Lenght } \\
\text { Sensor } \\
\text { ISO } \\
\text { Aperture } \\
\text { Shutter Speed }\end{array}$ & $\begin{array}{l}\text { Rule Of Third } \\
\text { Landscape } \\
\text { Eye Level } \\
\text { Mid Shot } \\
\text { Dslr/Mirrorless } \\
35 \mathrm{~mm} / 50 \mathrm{~mm} / 85 \mathrm{~mm} / 100 \mathrm{~mm} \\
\text { APSC/FullFrame } \\
100-200 \\
\mathrm{f} 1.2 / \mathrm{f} 1.4 / \mathrm{f} 1.8 / \mathrm{f} 2.8 \\
1 / 100-1 / 8000\end{array}$ \\
\hline \multirow[t]{8}{*}{ Gambar 6} & \multirow[t]{2}{*}{ Unsur Subjek Dan Objek } & Subjek & $\begin{array}{l}2 \text { orang, (pasangan yang sedang melakukan } \\
\text { pemotretan). }\end{array}$ \\
\hline & & Objek & $\begin{array}{l}\text { Sebuah Pertokoan sudah tidak digunakan } \\
\text { dan beberapa balok kayu. }\end{array}$ \\
\hline & \multirow[t]{6}{*}{ Unsur Tipografi } & Jenis Huruf & Sans Serif \\
\hline & & Ragam Huruf & Calibri \\
\hline & & Ukuran Huruf & $4,5 p t \& 1,5 p t$ \\
\hline & & Pengaturan Huruf & Horizontal \\
\hline & & & Scale $100 \%$ \\
\hline & & & Color Text : \#FFFFFF \\
\hline Jenis Gambar & Aspek Pengamatan & Sub Aspek & Keterangan \\
\hline \multirow{12}{*}{ Gambar 7} & \multirow[t]{10}{*}{ Unsur Fotografi } & Komposisi & Rule Of Third \\
\hline & & Format & Landscape \\
\hline & & Angel & Eye Level \\
\hline & & Type Shot & Mid Shot/Full Shot \\
\hline & & Camera Type & DsIr/Mirrorless \\
\hline & & Focal Lenght & $35 \mathrm{~mm} / 50 \mathrm{~mm} / 85 \mathrm{~mm} / 100 \mathrm{~mm}$ \\
\hline & & Sensor & APSC/FullFrame \\
\hline & & ISO & $100-200$ \\
\hline & & Aperture & $\mathrm{f} 1.2 / \mathrm{f} 1.4 / \mathrm{f} 1.8 / \mathrm{f} 2.8$ \\
\hline & & Shutter Speed & $1 / 100-1 / 8000$ \\
\hline & \multirow[t]{2}{*}{ Unsur Subjek Dan Objek } & Subjek & $\begin{array}{l}2 \text { orang, (pasangan yang sedang melakukan } \\
\text { pemotretan). }\end{array}$ \\
\hline & & Objek & $\begin{array}{l}\text { Keramaian perkotaan sukabumi, jalur } \\
\text { penyebrangan pejalan kaki (zebra cross). }\end{array}$ \\
\hline
\end{tabular}




$\begin{array}{lll}\text { Unsur Tipografi } & \text { Jenis Huruf } & \text { Sans Serif } \\ & \text { Ragam Huruf } & \text { Calibri } \\ & \text { Ukuran Huruf } & 4,5 p t \& 1,5 p t \\ & \text { Pengaturan Huruf } & \text { Horizontal } \\ & & \text { Scale 100\% } \\ & \text { Color Text : \#FFFFFF }\end{array}$

\section{Simpulan}

Setelah dilakukan proses pengumpulan data dengan metode kualitatif deskriptif dengan teknik studi pustaka dan observasi dapat disimpulkan bahwa konsep fotografi pre-wedding dengan penggabungan genre street fotografi pada foto Naturallica Photo merupakan sebuah konsep yang pada dasarnya merupakan sebuah kegiatan sehari-hari dari pasangan tersebut yang dengan sengaja didokumentasikan dalam bentuk foto.

Untuk mempertahankan definisi dari street photography itu sendiri maka tetap mempertahankan sebuah realitas yang ada tetapi dengan subjek diatur untuk melakukan pose oleh seorang fotografer. Street photography sendiri memiliki konsep yang sederhana dan menampilkan objek apa adanya tanpa dibuat-buat, namun hal tersebutlah yang menjadi keunikan dari foto tersebut.

Konsep ini diharapkan dapat digunakan seorang penyedia jasa fotografi ( vendor ) untuk menghadapi persaingan kreatifitas untuk menjadi penyedia jasa yang unggul, agar dapat melakukannya dengan baik maka diperlukan peralatan yang ringkas dan mumpuni serta mengetahui teknik pengambilan gambar, teknik pencahayaan, teknik komposisi, teknik exsposure dan editing yang baik pula.

\section{Daftar Pustaka}

Arief. 2011. "Tren Fotografi Pre-wedding"

Assyu, Aloysius. 2017. Estetika Fotografi Pada Karya Sebastiao Salgado Dalam Buku Beyond.

Cinantya, Ixsora Gupita. 2017. Kajian Visual Estetik pada Desain Kemasan Produk Cokelat UKM Kelompok Tani Elok Mekar Sari Surabaya. IDEA jurna desain.

Clement, Suzy. 2014. Weddings Dari Foto Biasa Jadi Luar Biasa. Jakarta : Indonesia PT Elex Media Komputindo.

\section{Dinprasetyo. 2017. Apa Itu Street photography?}

Enterprise, Jubile dan Ardiyanto Nugroho. 2012. Wedding Photography Hanbook. Jakarta : Indonesia PT Elex Media Komputindo.

Erlyana, \& Setiawan, 2019. Analisis Komposisi Fotografi Pada Foto Editorial "Elephants" Karya Steve Mccurry. Jurnal titik imaji.

Fredina, Erika, Arief Agung S, dan Adiel Yuwono. 2015 "Perancangan Fotografi Pre-wedding Gaya Dekonstruksi" Genesis.

Heryandi, Mochamad Rizky. 2019 "Pengertian, Ciri Khas dan Contoh Fotografi Jalanan (Street Photogaphy)"

http://fotografi.upi.edu/home/6-keahlian-khusus/street-photography 
http://publication. petra.ac.id/index.php/dkv/article/view/3313

http://www.infofotografi.com/blog/2015/08/definisi-street-photography/

https://ariefkosongsembilan.wordpress.com/2011/04/25/tren-fotografi-pre-wedding/

https://dinprasetyo.com/apa-itu-street-photography/

https://docplayer.info/184176787-Analisis-komposisi-fotografi-pada-foto-editorial-elephantskarya-steve-mccurry.html

https://www.seciko.com/pengertian-ciri-khas-dan-contoh-fotografi-jalanan-streetphotogaphy/

https://zona-photography.blogspot.com/2013/12/pengertian-sejarah-fotografi-jalanan.html

Isnaniah, Siti. 2020. “Covid-19” Meme In Social Media: Study Of Roland Barthes Semiology.

Middleton, Ian. 2015. A Practical Guide to Photography Basic Techniques For Beginners And

Mulyadi, asep dan azhar ma'arif. "Street photography"

Paulina Gunawan_Agnes. 2015. Pencahayaan Dalam Studio Fotografi.

Photography, zona. 2013. "Pengertian \& Sejarah Fotografi Jalanan (Street photography)"

Prasteyo, andy. 2012. Melukis Dengan Cahaya-Belajar Teknik Fotografi.

Tjin, Enche. 2015. "Definisi Street photography" 